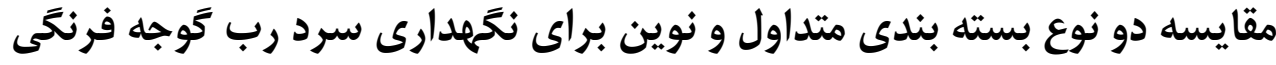

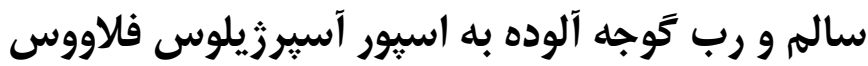

\author{
الناز يناهي "'، عليرضا موسوى"، مسعود سامى'، مريم ميرلوحى"

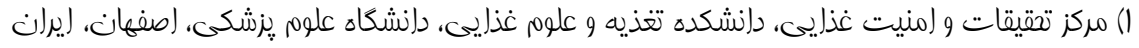

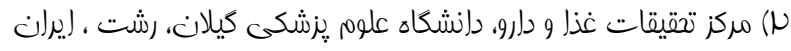

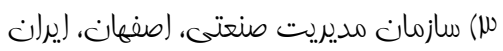

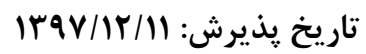

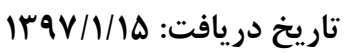

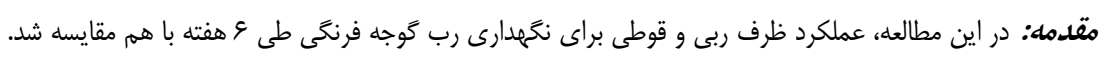

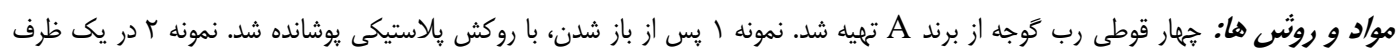

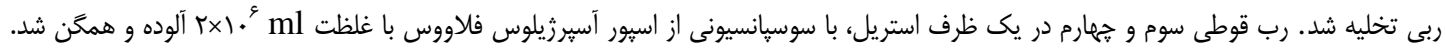

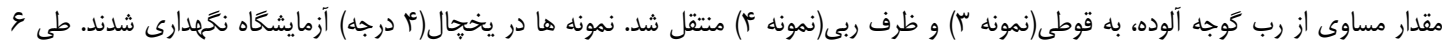

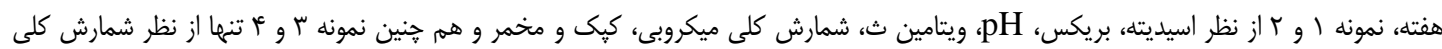

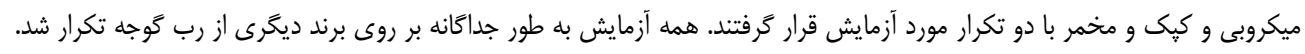

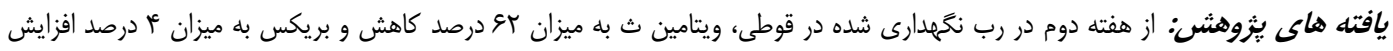

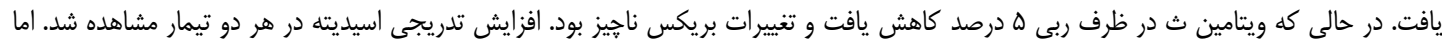

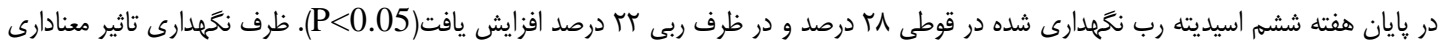

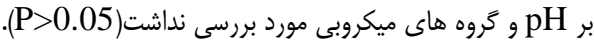

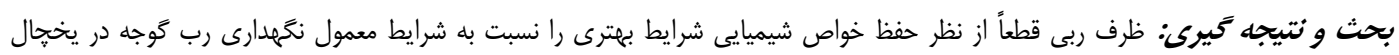

فراهم مى كند.

$$
\text { وازه هاى كليدى: رب گَوجه فرنگى، تغييرات ميكروبى، محصولات گَوجه فرنخى، تغييرات شيميايى }
$$

* نويسنده مسئول: مركز تحقيقات و امنيت غذايى، دانشكده تغذيه و علوم غذايى، دانشحاه علوم يزشكى، اصفهان، ايران Email:M_mirlohi@hlth.mui.ac.ir

Copyright (0) 2019 Journal of Ilam University of Medical Science. This is an open-access article distributed under the terms of the Creative Commons Attribution international 4.0 International License (https://creativecommons.org/licenses/by-nc/4.0/) which permits copy and redistribute the material, in any medium or format, provided the original work is properly cited. 
نامناسب و آلودگى ثانويه در يخجال، آلودگى قارجى آن مقدمه

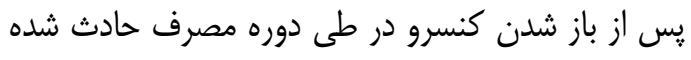

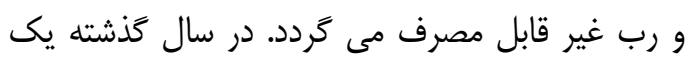

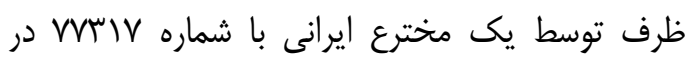

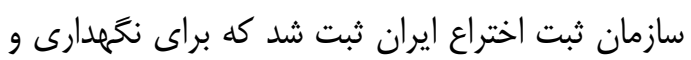

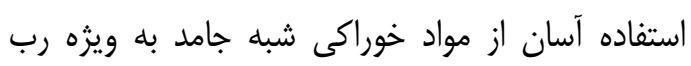

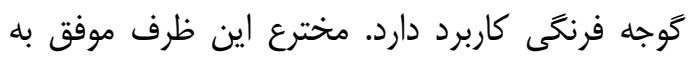

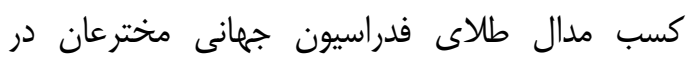
جشنواره»IENA 2016《 در آلمان شد. كاهش آلودئى

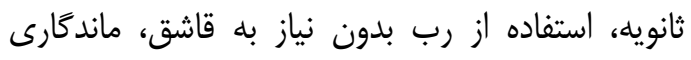
يك ماهه رب توسط توليدكننده ظرف ادعا شده است. اما اين ادعا تاكنون توسط روش هاى على علمى ثابت نشده

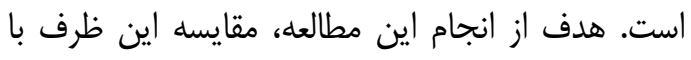

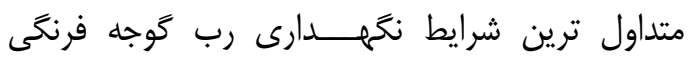
(نتخهدارى در قوطى اصلى و با دريوش هياستيكى)

\section{مواد و روش هات}

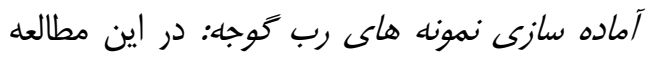

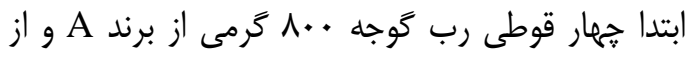
يك سرى ساخت تهيه شد. نمونه ا بله شكل معمول باز

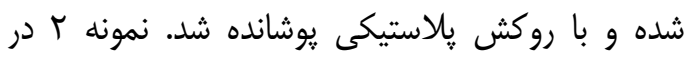
يك ظرف ربى كه قبلاً بخار ديده و زير نور

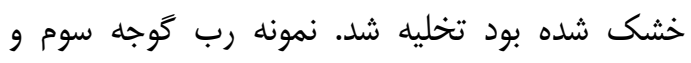

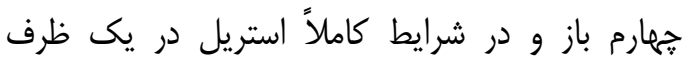

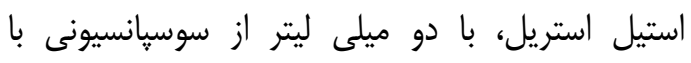
غلظت ". اسبور آسيرزيلوس فلاووس در هر ميلى لئل ليتر

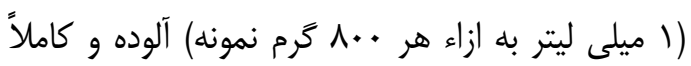

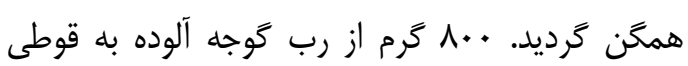

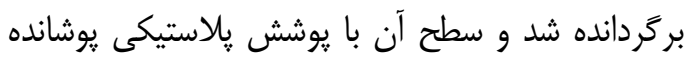

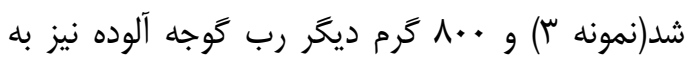

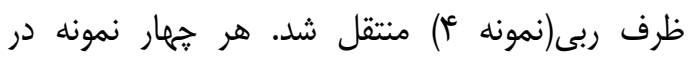
يخجالى با دماى أ درجه در آزمايشگاه دانشكده تغذيه،

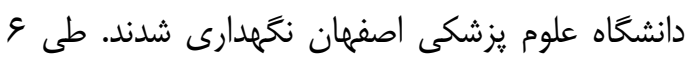

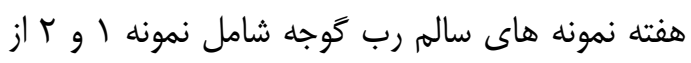

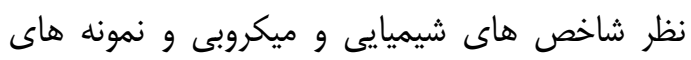

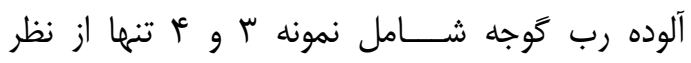

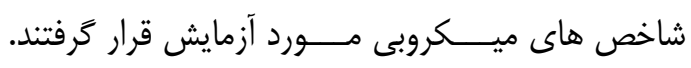
شاخص هاى ميــكروبى شامل شمارش كلى ميكروبى، مئى

خوجه فرنكى در ميان غذاهاى گياهى به صورت

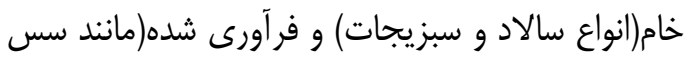

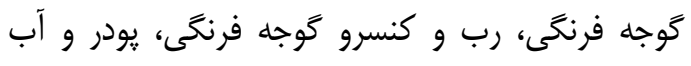
كوجه) به علت حضور تركيبات عملكردى ماند مانند ليكوين، بتاكاروتن، اسيد اسكوربيك و تركيبات فنلى بالاترين محبوبيت را در بين مردم در سراسر دنيا دارد(1). نتايج

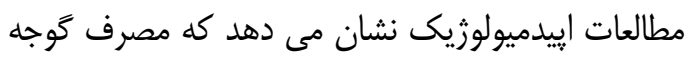
فرنكى و محصولات آن با افزايش سطح ليكوين خون

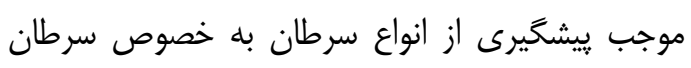

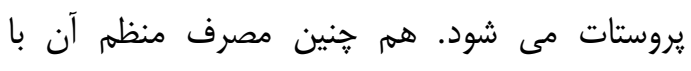

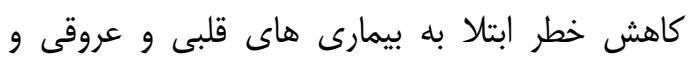

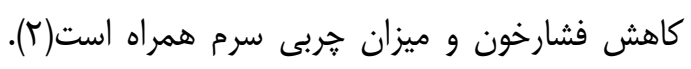

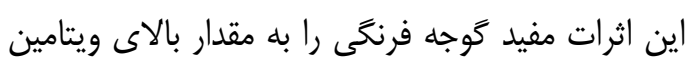

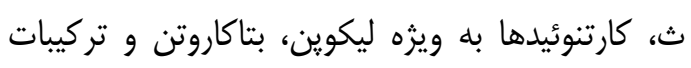

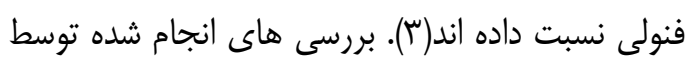

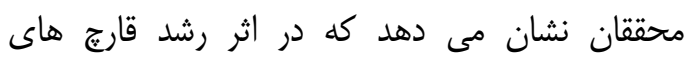

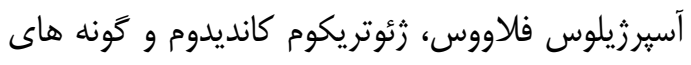

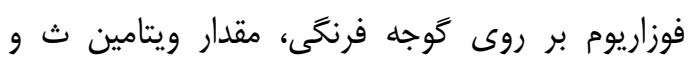

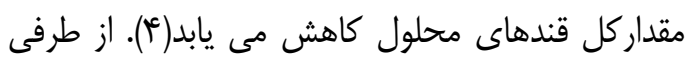

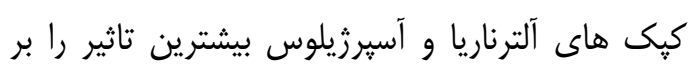

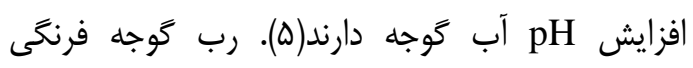

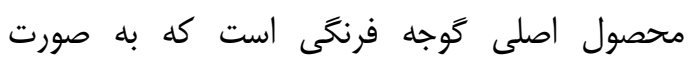

تجارى يا به صورت سنتى در منزل تهيه مى شود(و).

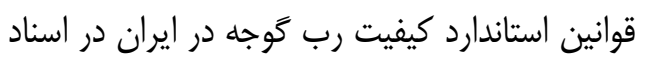

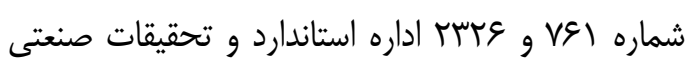

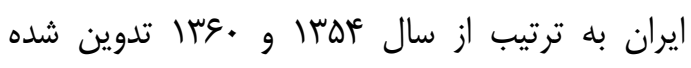

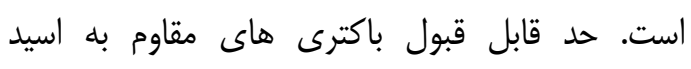

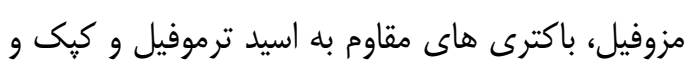

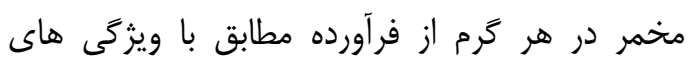
ميكروبيولوزى مواد غذايى اسيدى يا اسيدى شدر شده در

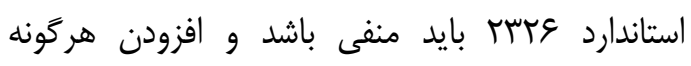

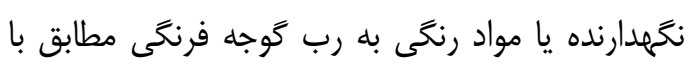

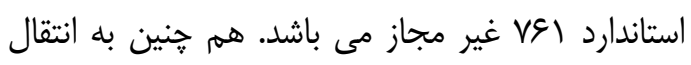

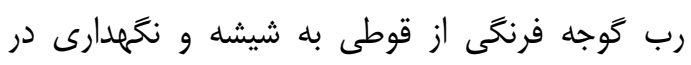

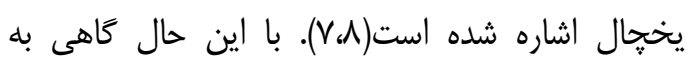

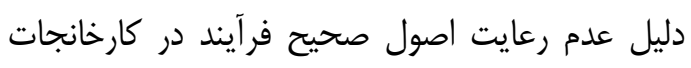

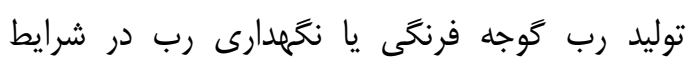


ع آزمون، شامل دو تكرار هر يك از آزمايشات شيميايى

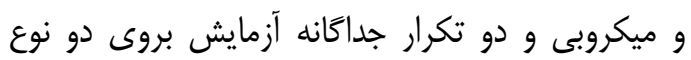

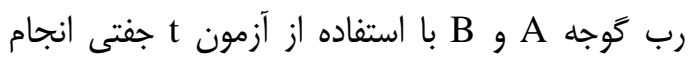

\section{يافته هاى يزوهث}

نتايج بررسى و مقايسه تغييرات شيميايى رب گورجه در ظرف ربى و قوطى(نمونه ( و نمونه r) طى 9 هفته

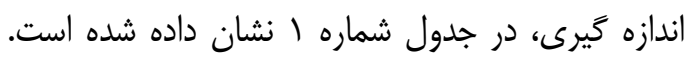

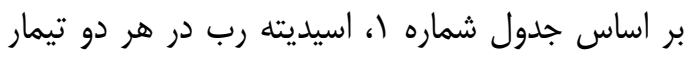

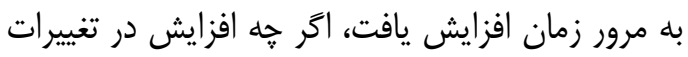
اسيديته از هفته دوم مطالعه در رب نكمهدارى شده در قوطى به طور نسبى بيشتر بود. اما تفاوت معنادار بين

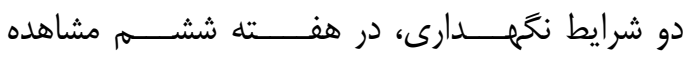

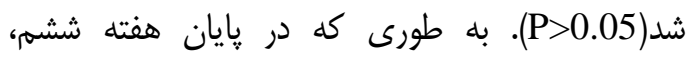

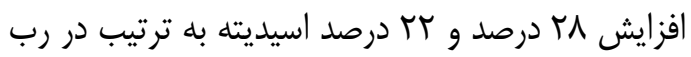

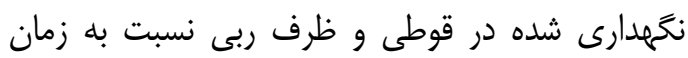
اوليه مشاهده شد.

مقايسه تغييرات pH در دو نمونه حاكى از عدم تـــفاوت در كــيفـــــيت pH بين دو روش نكخهدارى

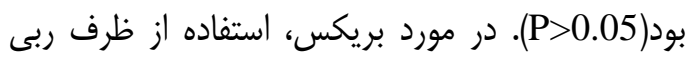

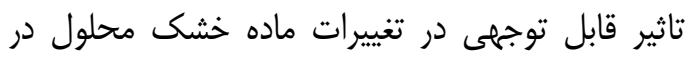
رب داشت. بله طورى كه از هفته دوم، افزايش بر بريكس

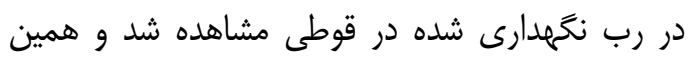

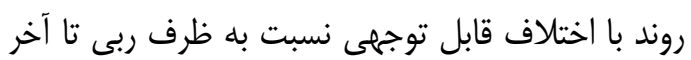

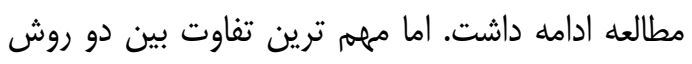

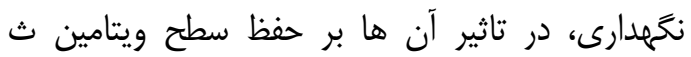
مشاهده شد. به طورى كه تفاوت قابل توجه غلظت

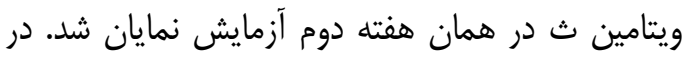

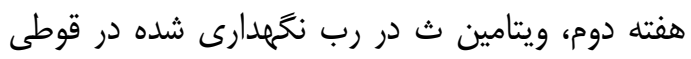

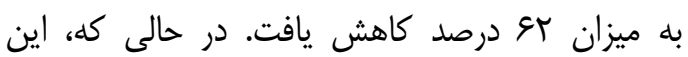

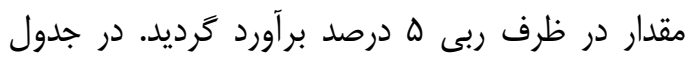

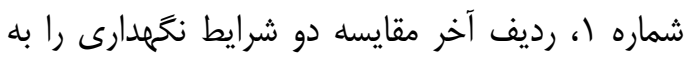
طور كلى و بدون در نظر كرفتن اثر زمــــان نـــشان

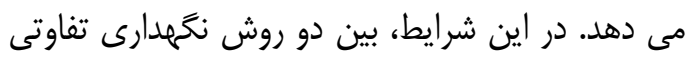

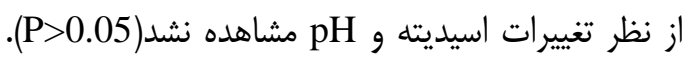

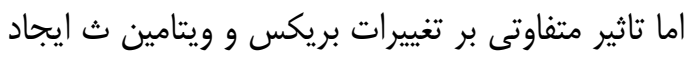
كردند(P<0.05)
كيى و مخمر و شاخص هاى شيميايى شامل اندازه

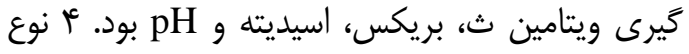

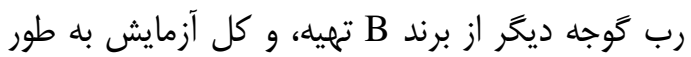
جداكانه بر روى آن تكرار شد.

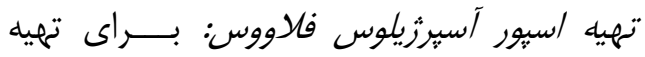
محلول حاوى اسيور قارج، ابتدا كونه استــــــــاندارد آسيرزيلوس فلاووس روى محيط كشت سابرودكستروز

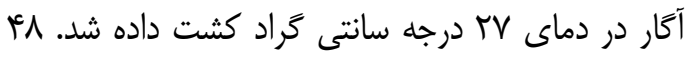
ساعت پֶ از رشد كيك، r سى سى آب مقطر استريل بر روى محيط كشت اضافه شد. سوسيانسيون تهيه

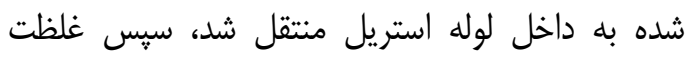

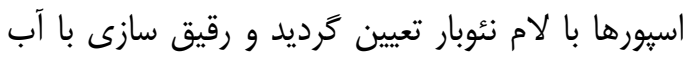

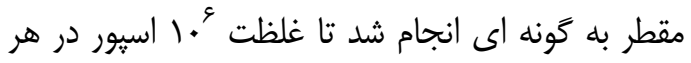

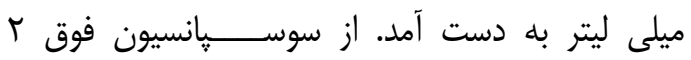
ميلى ليتر به دو نمونه از رب صنــــتى تلقيح شد.

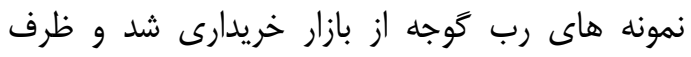
نكمهدارنده رب توسط شركت توليد كننده ربى فراهم

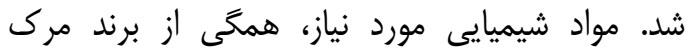
(آلمان) تهيه شدند.

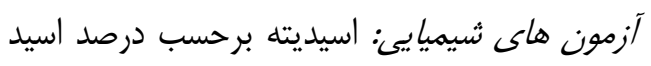
سيتريك به روش تيتراسيون حجمى با استفاده ازسود

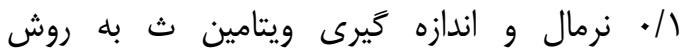
تيتراسيون با استفاده از رنگ كلروفنل ايندوفنل طبق

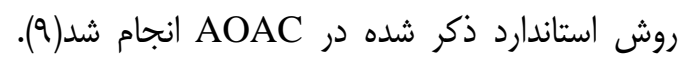

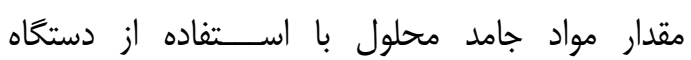

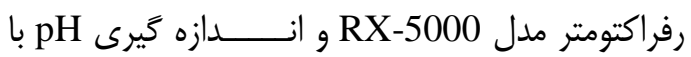

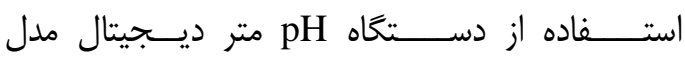

Meter PP-50Professional آزمون هاى ميكروبى: شمارش كلى باكترى ها با

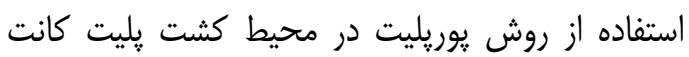

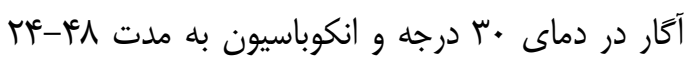

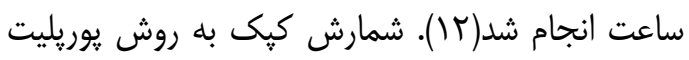

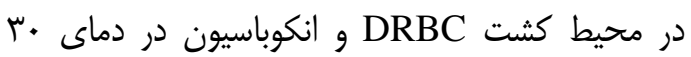
درجه به مدت س روز انجام شد(سا) تجزيه و تحليل آمارى: تحليل و مقايسه ميانگين

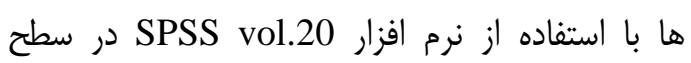
معنى دارى(P<0.05) انجام شد. مقايسه ميانخين نتايج 
جدول شماره ا. مقايسه تغييرات شيميايى رب توجه در دو ظرف ربى و قوطى

\begin{tabular}{|c|c|c|c|c|c|}
\hline ويتامين ث(mg/100g) & بريكس & $\mathrm{pH}$ & اسيديته(mg/100g) & تيمار & روز - إز \\
\hline$r \nu / . \varphi \pm r / v$. & $r V / \uparrow \wedge \pm \cdot / / \Lambda$ & $r / V T \pm \cdot / r I$ & $1 / V \Delta \pm \cdot / T \Delta$ & 1 & - \\
\hline$r M / . \varepsilon \pm 1 / 1$. & $r V / r \cdot \pm \cdot / \cdot r$ & $r / N \Psi \cdot / r \Delta$ & $1 / q T \pm \cdot / 4 T$ & t & \\
\hline $\mathrm{t}(\varphi)=\cdot ، \mathrm{P}=\cdot / \wedge r$ & $\mathrm{t}(T / r)=1 / 99 ، \mathrm{P}=. / / \mu r$ & $\mathrm{t}((\varepsilon)=\cdot / \varepsilon q, \mathrm{P}=\cdot / \Delta \varphi$ & $\mathrm{t}(\Delta / १ १)=-1 / \cdot \wedge, \mathrm{P}=\cdot / \mathrm{r}$ & & \\
\hline$|9 / 91 \pm \cdot / 4|$ & $T V / V Y \pm \cdot / r \Delta$ & $r / V T \pm \cdot / 1 q$ & $\cdot / \mid \varepsilon \pm r / \|$ & 1 & \multirow[t]{3}{*}{ If } \\
\hline$N / \cdot T \pm I / T \Delta$ & 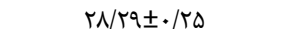 & $r / \Lambda \cdot \pm \cdot / \cdot 1$ & $r / \uparrow \wedge \pm \cdot / /$ & r & \\
\hline$t(\varepsilon)=I V / q ، P=\cdot /$ & $\mathrm{t}(r / \Lambda)=-r / F), \mathrm{P}=. / . q r$ & $\mathrm{t}(\varepsilon)=\mathrm{I} / \cdot \Lambda \mathrm{P}=\cdot / \mathrm{rr}$ & $t(r / \varepsilon)=-1 / 9 \varphi \cdot P=\cdot / / r$ & & \\
\hline$I V / T F \pm T / F \Delta$ & $T V / r q \pm \cdot / 1 I$ & $r / \Lambda \cdot \pm \cdot / \Lambda \cdot$ & $T / T V \pm * / T \Delta$ & 1 & \multirow[t]{3}{*}{ rᄉ } \\
\hline$\Delta / V^{c} \pm 1 / V \Lambda$ & $r \Delta \pm . / 4\rangle$ & $r / \Lambda) \pm . / \cdot 1$ & $T / r V \pm \cdot / T F$ & r & \\
\hline $\mathrm{t}(\varepsilon)=\mid \varepsilon / 1 ، \mathrm{P}=$ & $\mathrm{t}(\varepsilon)=-r / \kappa, \mathrm{P}=. / \cdot r$ & $t(\Delta / 1)=-1 / 99, P=\cdot / 1 \Delta$ & $\mathrm{t}(\varphi)=-\cdot / \Delta \varphi, \mathrm{P}=\cdot / \Delta \mid$ & & \\
\hline$\| f / / f \pm r / \Lambda \Delta$ & $r V / r q \pm \cdot / 1 D$ & $r / V I \pm \cdot / r \mu$ & $r / I r \pm \cdot / I I$ & 1 & \multirow[t]{3}{*}{ et } \\
\hline$r / \cdot r \pm \cdot / q q$ & $r N / T \cdot \pm \cdot / T \Lambda$ & $\Gamma / \Delta \wedge \pm \cdot / \Gamma \varepsilon$ & $T / \digamma \wedge \pm \cdot / T \digamma$ & r & \\
\hline $\mathrm{t}(\varphi)=V / \wedge V_{6} \mathrm{P}=$ & $t(\varphi)=-\Delta / q \vee$ ، $P=\cdot / .$. & $t(\Delta / Q)=\cdot, P=\cdot / \Delta r$ & $t(\varphi)=-1 / 9, P=. / \cdot r$ & & \\
\hline$W / \cdot q \pm r / T V$ & $r V / \Delta \cdot \pm \cdot / T q$ & $r / V \Delta \pm \cdot / / \Delta$ & $T / r T \pm \cdot / \mathscr{T}$ & 1 & \multirow[t]{3}{*}{ Total } \\
\hline$Q / \leftarrow \varepsilon \pm V / T V$ & $r V / Q ९ \pm \cdot / \kappa r$ & $r / V \Delta \pm \cdot / 19$ & $r / G T \pm \cdot / \mathscr{A} D$ & r & \\
\hline$t(r \cdot)=-1 / 9, P=\cdot /$. & $t(r q)=-r \cdot P=\cdot / \cdot r \Lambda$ & $\mathrm{t}(r \cdot)=\cdot / \Delta q, \mathrm{P}=\cdot / \mathrm{Q} \Delta$ & $t(r \cdot)=-1 / 9, P=\cdot / \cdot 9$ & & \\
\hline
\end{tabular}

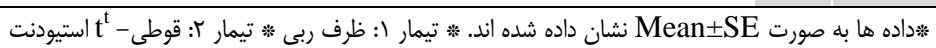

نمونه تا קيايان هفته ششم مشاهده نشد. مقايسه

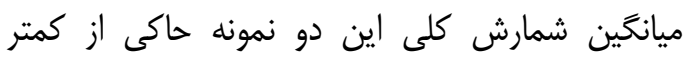

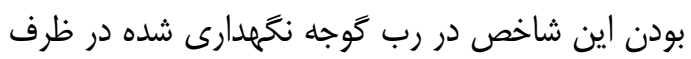
ربى بود، با اين حال اين تفاوت از نظر آمارى در هيج

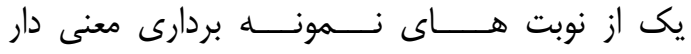

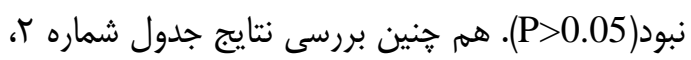
حاكى از كاهش تدريجى شمارش كلى ميكروبى و

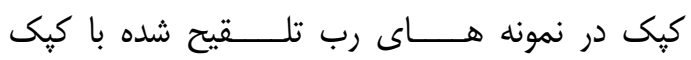
بود. با وجود بالاتر بودن ســــــرعت كاهش در نمونه

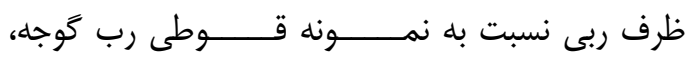

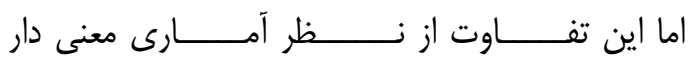
نبود (P>0.05).
جدول شماره r نتايج مقايسه استفاده از ظرف ربى با شرايط معمولى قوطى رب بر رشد ميكروبى در دو سور

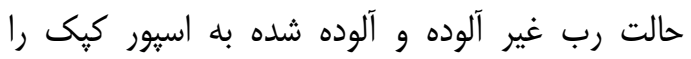
نشان مى دهد. در ابتداى مطالعه نمونه هاى رب رَّل

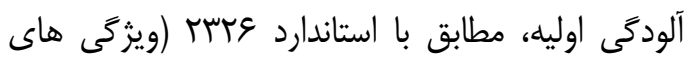

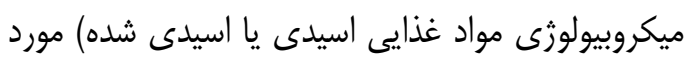

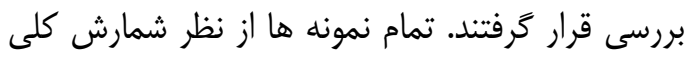
ميكروبى و كيك فاقد آلودگى تشخيص داده شدند. بر اساس نتايج جدول شماره r، رشد جمعيت ميكروبى در

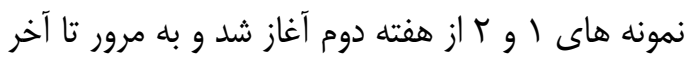

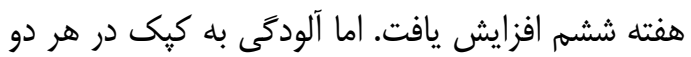

\begin{tabular}{|c|c|c|c|c|c|}
\hline i & $r$ & r & 1 & تيمار & هفته \\
\hline$T / E T E T / M Y F$ & $r / r q \pm r / l r$ & . & . & شمارش كلى ميكروبى & \\
\hline$r / \Psi A \pm T / / V$ & $r / F r \pm T / I Q$ & . & . & شمارش كيك و مخمر & \\
\hline$r / r V \pm 1 / q \Delta$ & $r / r q \pm 1 / \wedge r$ & $\cdot / 89 \pm \cdot / 4 V$ & $\cdot / r q \pm . / \Delta F^{c}$ & شمارش كلى ميكروبى & \multirow{2}{*}{$r$} \\
\hline$r / r \Delta \pm 1 / V r$ & $r / F \backslash \pm Y / I V$ & · & - & شمارش كيك و مخمر & \\
\hline$r / r \Psi \pm 1 / v q$ & $r / r V \pm r / \cdot q$ & $1 / \Gamma \Delta \pm \cdot / \Lambda$ & $1 / \Delta \Lambda \pm 1 / r \mid$ & شمارش كلى ميكروبى & \multirow{2}{*}{$f^{r}$} \\
\hline 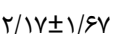 & $r / T \Delta \pm 1 / \Delta S$ & . & . & شمارش كيك و مخمر & \\
\hline$r / / r \pm 1 / \wedge q$ & $r / r \varepsilon \pm r / / q$ & $|/ r| \pm 1 / T r$ & $1 / \Delta \Lambda \pm 1 / \mu^{c}$ & شمارش كلى ميكروبى & \multirow{2}{*}{8} \\
\hline$r / \cdot q \pm 1 / 8 V$ & $r / T F \pm 1 / 9 \varepsilon$ & . & $\cdot$ & شمارش كيك و مخمر & \\
\hline
\end{tabular}


اتاق و نكَهدارى در ظروف در بسته نسبت به ظروف در باز ميزان تلفات ويتامين ث را كاهش مى دهد(هان). الهامى راد و شهيدى در مطالعه خود نيز نشان دادند كه

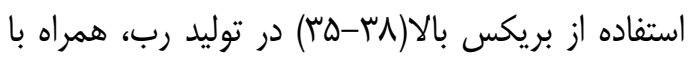
عمل نمك ياشى در سطح و نكَهدارى در دماى صفر درجه سانتى گراد فقط يك اثر محدودكننده بر روند تغييرهاى ميكروبى داشته ولى به طور كامل باعث توقف آن نشد(ع)). در همين راستا هاشمى و همكاران

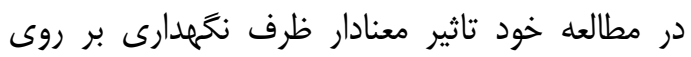

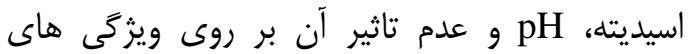

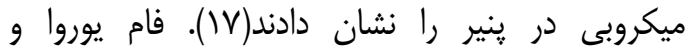

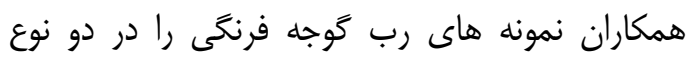

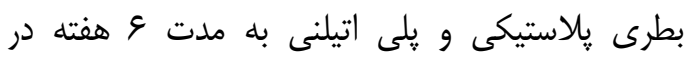

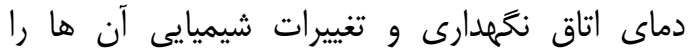
بررسى كردند. در همه نمونه ها افزايش قابل توجه

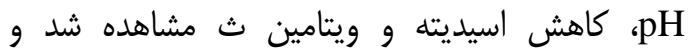

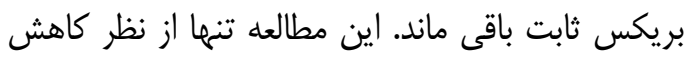

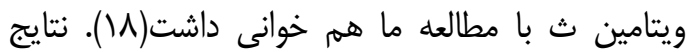
مطالعه ما با نتايج يزوهش جوزف و همكاران، در زمينه

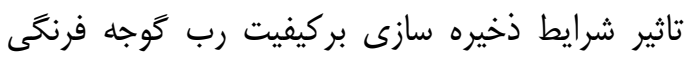

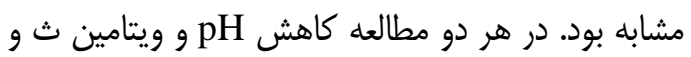
افزايش اسيديته در تمام نمونه ها مشاهده شد(19).

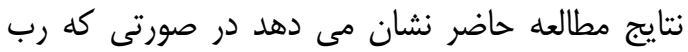

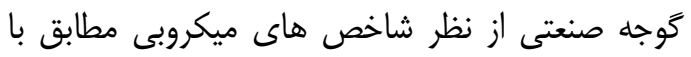
استاندارد باشد و جمعيت ميكرواركانيسم هاى اونيك اوليه بسيار كم باشد، استفاده از ظرف ربى و قوطى رب ريكان تفاوت جندانى در رشد ميكرواركانيـسم ها ايــــاد نمى كند. البته بايد توجه داشت كه در اين مطالعه شرايط نتحهدارى تنها شرايط يخهال آزمايشگاه در نظر

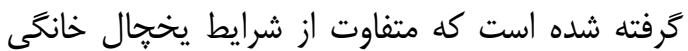

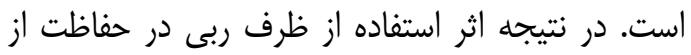

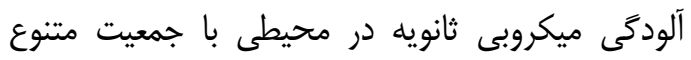

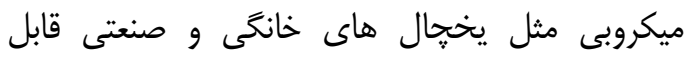
تعميم نيست. نتيجه كلى به دست آمده از نمونه هاى رب تلقيح شده با كيى برخلاف انتظار، نشان دهنده

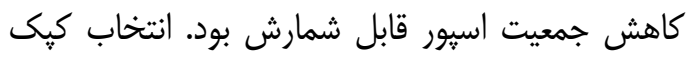

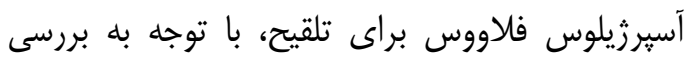

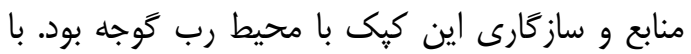

\section{بحث و نتيجه تيرى}

مطالعه حاضر نشان مى دهد استفاده از ظرف رئرى جهت نكمهدارى رب گوجه فرنكى موجب حفظ ماده خشك محلول و غلظت ويتامين ث رب تازه مى شود.

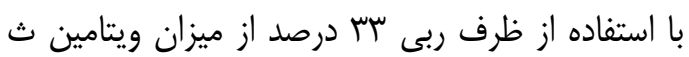
بعد از 9 هفته نكَمدارى كاسته شد. اما در شرايط عادى إدى

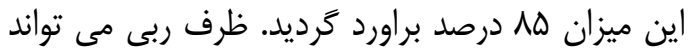

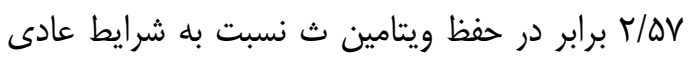

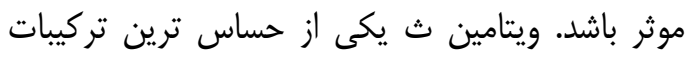

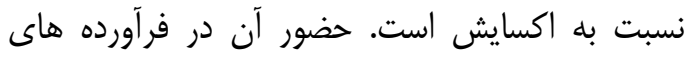
كوجه فرنكى نه تنها برآوردى از ارزش غذايى است

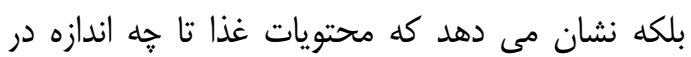

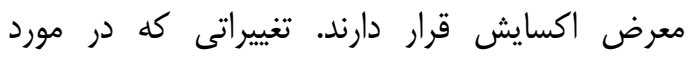
اسيديته در نتايج اين مطالعه به دست آمد، مى تواند ناشى از تاثير شرايط نكَمدارى بر تغييرات ماده خشى

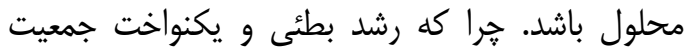

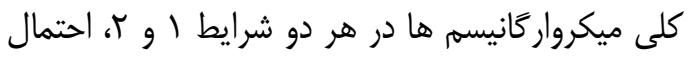
ميكروبى بودن منـــشاء تغييرات اسيديته را بسيار كم مى كند. در عين حال، تغييرات pH به اين شكل قابل توجيه است كه تغييرات اسيديته به حدى نبوده كه

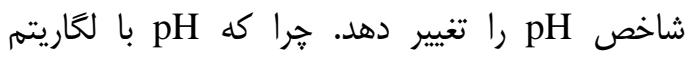
غلظت يون هيدروثن متناسب بوده و براى مشاهده تغييرات، احتياج به تغييرات بيشترى از غلظت اسيد است. در سال .... صفدر و همكاران با مطالعه تاثير زمان و دما بر ويزگى هاى كيفى رب گَوجه كزارش

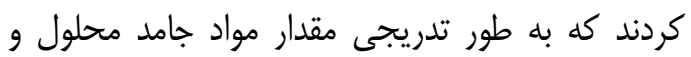
اسيديته افزايش، در حالى كه pH و ويتامين ث كاهش

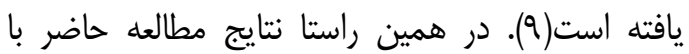

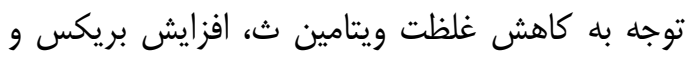

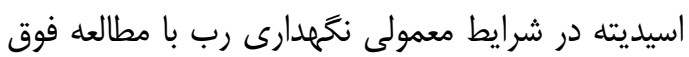
هم خوانى دارد. نتايج يزوهش ما از نظر نتخهدارى رب ابل كوجه در ظرف ربى و حفظ درصد بالايى از ويتامين ثان آثارئ با نتايج مطالعه فرانسيسكو و همكاران و كابازاكاليس و و وراني

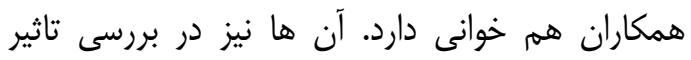

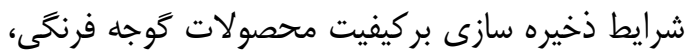

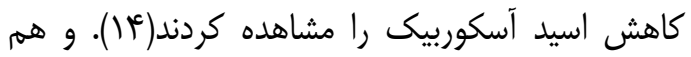
קنين كابازاكاليس و همكاران نشان دادندكه نكمهدارى

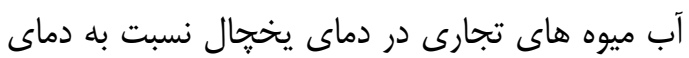




$$
\begin{aligned}
& \text { اسيديته كم نشان دهنده خواص مناسب نفوذنايذيرى }
\end{aligned}
$$

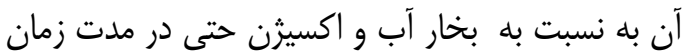

$$
\begin{aligned}
& \text { طولانى است. مقايسه عملكرد ظرف ربى بار با قوطى إنى }
\end{aligned}
$$

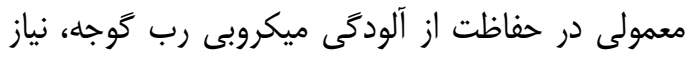

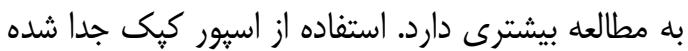

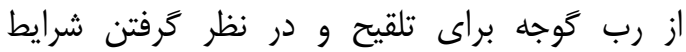

$$
\begin{aligned}
& \text { نُخهدارى رب در يخجال هاى خانكَى در مطالعات آينده } \\
& \text { مى تواند نتايج متفاوتى را در اين باره ارائه كند. }
\end{aligned}
$$

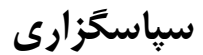

$$
\begin{aligned}
& \text { بدين وسيله از همكارى مركز تحقيقات امنيت } \\
& \text { غذايى، دانشكده تغذيه و علوم غذايى دانشخاه علوم } \\
& \text { يزشكى اصفهان تشكر و قدردانى مى گردد. اين مقاله }
\end{aligned}
$$

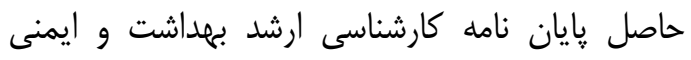

$$
\begin{aligned}
& \text { مواد غذايى با كد اخلاقى سـهیهوس مى باشد. }
\end{aligned}
$$

\section{References}

1.Dermesonlouoglou EK, Andreou V, Alexandrakis Z, Katsaros GJ, Giannakourou MC, Taoukis PS. The hurdle effect of osmotic pretreatment and high pressure cold pasteurisation on the shelf life extension of fresh cut tomatoes. Int $\mathrm{J}$ Food Sci Technol 2017;52:91626. doi:10.1111/ijfs. 13355

2.Borguini RG, Ferraz EA. Tomatoes and tomato products as dietary sources of antioxidants. Food Rev Int 2009;25:313-25. doi:10.1080/87559120903155859

3.Toor RK, Savage GP. Changes in major antioxidant components of tomatoes during post harvest storage. Food Chem 2006;99:724-

7.doi:10.1016/j.foodchem.2005.0800.049

4. Oladiran A, Iwu L. Changes in ascorbic acid and carbohydrate contents in tomato fruits infected with pathogens. Plant Food Hum Nut 1992;42:373-82. doi: 10.1007/BF02194098

5. Mundt JO. Effect of mold growth on the $\mathrm{pH}$ of tomato juice. $\mathrm{J}$ Food Prot 1978;41:267-8.doi: $\quad$ 10.4315/0362-028X41.4.267

6.Capanoglu E, Beekwilder J, Boyacioglu $\mathrm{D}$, Hall R, Vos R. Changes in antioxidant and metabolite profiles during production of tomato paste. J Agr Food Chem 2008;56:964-73.doi: 10.1021/jf072990e

$$
\begin{aligned}
& \text { اين حال شايد اسيديته بالا و مناسب نبودن محيط رب } \\
& \text { گوجه مانع از رشد اين كيك در طى نكَهدارى شده } \\
& \text { است. شايان ذكر است كه هر دو برند مورد مطالعه از }
\end{aligned}
$$

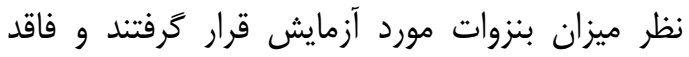

$$
\begin{aligned}
& \text { بنزوات تشخيص داده شدند. در هر صورت، روند كاهش } \\
& \text { كيى ها در ظرف ربى با سرعت بيشترى نسبت به }
\end{aligned}
$$

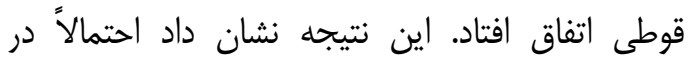

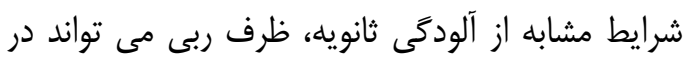

$$
\begin{aligned}
& \text { فراهم كردن محيط نامساعدى براى كاهش جمعيت } \\
& \text { آلاينده موثرتر از روش نتحهدارى معمول رب در قوطى إنى }
\end{aligned}
$$

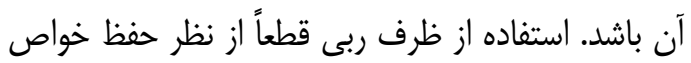

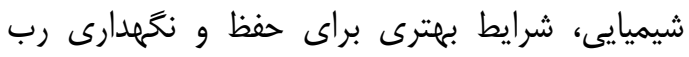

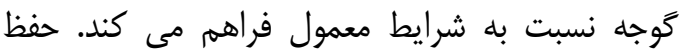

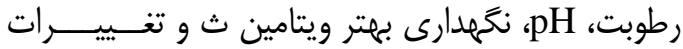

7.Institute of standards and industrial research of Iran. Microbiology of Canned foods- commercial sterility specifications and test methods. $1^{\text {th }}$ ed. 2017;P. 232-6.

8.Institute of standards and industrial research of iran. Canned tomato pastespecifications and test methods. $1^{\text {th }}$ ed. 2016;P.761

9.Safdar MN, Mumtaz A, Amjad M, Siddiqui N, Hameed T. Development and quality characteristics studies of tomato paste stored at different temperatures. Pak J Nut 10.3923/pjn.2010.265.268

10.Moreno C, Plaza L, Ancos B, Cano MP. Nutritional characterisation of commercial traditional pasteurised tomato juices carotenoids vitamin $\mathrm{C}$ and radical scavenging capacity. Food Chem 2006;98:749-56.doi:

10.1016/j.foodchem.2005.07.015

11.Akıllioglu HG, Bahceci KS, Gokmen V. Investigation and kinetic evaluation of furan formation in tomato paste and pulp during heating. Food Res Int 2015;78:22430. doi: 10.1016/j.foodres.2015.10.005

12.Kilinc B, Cakli S. Determination of the shelf life of sardine Sardina pilchardus marinades in tomato sauce stored at $4 \mathrm{C}$. Food Control 2005;16:639-44. doi: 10.1016/j.foodcont.2004.07.004 
13.Umme A, Salmah Y, Jamilah B, Asbi B. Microbial and enzymatic changes in natural soursop puree during storage. Food Chem 1999;65:315-22. doi: 10.1016/S03088146(98)00215-5

14.Frusciante L, Barone A, Carputo D, Ercolano MR, della Rocca F, Esposito S. Evaluation and use of plant biodiversity for food and pharmaceuticals. Fitoterapia 2000;71:S66-S72. doi: 10.1016/S0367326X(00)00175-1

15.Kabasakalis V, Siopidou D, Moshatou E. Ascorbic acid content of commercial fruit juices and its rate of loss upon storage. Food Chem 2000;70:325-8. doi: 10.1016/S0308-8146(00)00093-5

16.Elahamirad AH, Shahidi F. [Evaluation of physicochemical and microbial changes of bulk tomato paste in cold storage]. J Sci Technol Agr Nat Res 2004;8:88-171. (Persian)
17.Hashemi M, Tabatabaee YF, Yavarmanesh M, Milani E, Pasban A. [Effect of rennet type container and ripening period on physicochemical and microbial properties of local Kurdish cheese]. J Food Sci Technol 2013;9:135-47. (Persian)

18.Famurewa J, Ibidapo $\mathrm{P}$, Olaifa $\mathrm{Y}$. Storage stability of tomato paste packaged in plastic bottle and polythene stored in ambient temperature. Int J Appl 2013;3:3442. doi: 10.5897/AJFS2014.1242

19.Joseph A, Agomuo J, Alaka I. Storage stability of tomato paste as influenced by oil-citric acid and packaging materials. Af $\mathbf{J}$ Food Sci 2015;9:120-5. doi: 10.5897/AJFS2014.1242 


\title{
Comparison of Conventional and Modern Packaging in the Cold Storage of Healthy Tomato Paste and Tomato Paste Contaminated with Aspergillus flavus Spore
}

\author{
Panahi $E^{1,2}$, Mousavi $A^{3}$, Sami $M^{1}$, Mirlohi $M^{1 *}$
}

(Received: 4 April, 2018

Accepted: 2 March, 2019)

\begin{abstract}
Introduction: This study aimed to compare the storage stability of tomato paste packaging of cans and a container with the brand name of "Robby" during 6 weeks.

Materials \& Methods: Four cans of tomato paste were prepared from brand A. Sample 1 was covered with the plastic lid after opening. Sample 2 was transferred into a container with the brand name of "Robby". Tomato paste of cans 3 and 4 were contaminated with Aspergillus flavus spore ssuspension (t $2 \times 10^{6}$ spore $/ \mathrm{ml}$ ) and homogenized in a sterile container. Subsequently, an equal amount of contaminated tomato paste was transferred into the original can (sample 3) and the "Robby" container (sample 4). Samples were stored in a refrigerator at $4^{\circ} \mathrm{C}$ for 6 weeks. Samples 1 and sample 2 were evaluated regarding acidity, Brix, $\mathrm{pH}$, vitamin $\mathrm{C}$, as well as total bacteria, mold, and yeast count. However, samples 3 and 4 only were analyzed in terms of total bacteria, mold, and yeast count with two replications. All the experiments were individually repeated on another tomato
\end{abstract}

paste with a different brand name. Ethics code: 395833

Findings: After the second week, there was a $62 \%$ decrease and a $4 \%$ increase in vitamin $\mathrm{C}$ and Brix levels in the tomato paste in the can. However, the reduction in vitamin $\mathrm{C}$ level $(5 \%)$ and the Brix changes were not significant in the "Robby" container. The gradual increase of acidity was observed in both treatments. Nevertheless, there was an increase in the acidity of the tomato paste kept in the can (28\%) and "Robby" container (22\%) at the end of the sixth week $(\mathrm{P}<0.05)$. The "Robby" container had no significant effect on $\mathrm{pH}$ and microbial groups $(\mathrm{P}>0.05)$.

Discussion \& Conclusions: The "Robby" container definitely provides better conditions for preserving the chemical properties of tomato paste than common means of tomato paste storage.

Keywords: Chemical change, Microbial changes, Tomato paste, Tomato products

1. Food Safety Research Center, Faculty of Nutrition and Food Sciences, Isfahan University of Medical Sciences, Isfahan, Iran

2. Food nd Drug Research Center, Guilan University of Medical Sciences, Rasht, Iran

3.Industrial Management Organization, Isfahan, Iran

*Corresponding author Email: M_mirlohi@hlth.mui.ac.ir

Scientific Journal of Ilam University of Medical Sciences 